\title{
EDITORIAL
}

\section{Preocupante Balance 2011}

Al finalizar el año cabe realizar un balance de lo ocurrido en salud durante el periodo. La Revista Chilena de Salud Pública considera que algunos de los problemas sanitarios vividos durante el 2011 dan cuenta de un curso, que de no ser corregido, se traduce en la persistencia y exacerbación de las barreras en el acceso a servicios, bienes y prestaciones en el mundo del tratamiento de la enfermedad.

Esta situación es preocupante, porque mientras en la red de salud se han acentuado las dinámicas de fragmentación, bajo la guía de consideraciones centradas en la gestión de los hospitales, como unidades independientes de la atención primaria, se impone un creciente énfasis de las compras a privados, sin atención a definiciones estratégicas sobre el fortalecimiento de la red asistencial pública, la inversión sectorial, la formación de recursos humanos, la constitución de polos de desarrollo y la articulación de macrozonas interregionales. Además, el acento en un manejo guiado unilateralmente por costos, sustituyendo el desarrollo de los procesos clínicos y el cultivo de la diversidad local, pone a los establecimientos hospitalarios en una lucha por la sobrevida financiera, que no augura ni equidad ni cooperación.

Acceso, adecuación local, equidad geográfica, étnica, de género y coordinación de la red asistencial son palabras cada vez más ausentes en el mapa conceptual actual. Ausencia que las cifras proporcionadas por las dos principales encuestas divulgadas este año, Encuesta Nacional de Salud (ENS) y Encuesta Nacional de Consumo Alimentario (Enca), señalan que la tijera entre una red que no logra ofrecer prestaciones adecuadas, accesibles y la magnitud de problemas sanitarios existentes, se continúa abriendo. La reunión ONU-OMS sobre enfermedades no transmisibles agregó relevancia global e institucional al problema, pero siguen pendientes las decisiones políticas nacionales que transformen las cifras de alarma en acción.

No podemos cerrar este editorial sin señalar las difíciles condiciones de la educación chilena en todos sus niveles y -en nuestro caso- las implicancias sobre la formación de pre y posgrado en salud pública. La situación sostenida por meses no ha dejado indemne los programas de formación, investigación y extensión del campo disciplinar. En cuanto a la investigación, aun cuando los fondos sectoriales estén creciendo significativamente (Fonis), la transformación de esos proyectos en producción científica, evidencia y herramientas decisoras se mantiene marginal, como ha quedado en evidencia en la $2^{\circ}$ Conferencia Latinoamericana sobre Investigación e Innovación para la Salud realizada recientemente en Ciudad de Panamá. 
Ciertamente, las tareas de la salud pública no cambiarán de año en año, pero es deseable y necesario ordenar itinerarios y coordinar iniciativas. El desafío editorial de la Revista Chilena de Salud Pública considera convocar al estudio y publicación en sus páginas de artículos acerca del trabajo en red de establecimientos, servicios, regiones y macrozonas.

Giorgio Solimano

Director

Yuri Carvajal

Editor 